\title{
Vibration and Temperature Measurement Based Indicator of Journal Bearing Malfunction
}

\author{
Ranko ANTUNOVIĆ, Amir HALEP, Mihael BUČKO, Sreten PERIĆ, Nikola VUČETIĆ
}

\begin{abstract}
This paper aims to present the development and implementation of the new malfunction indicator in journal bearings, based on vibrational and thermal records, called DFJB-Defect Factor Journal Bearing. Briefly, the indicator contains the specifically processed information about the bearing vibrations and temperature, on the basis of which the DFJB is calculated using fuzzy logic, and thus the state of the journal bearing may be determined. It should be pointed out that the DFJB is developed in a manner that besides the temperature and the total number of absolute vibrations, it may also integrate following parameters of monitoring: the parameters of rotating vibrations, vibrations spectrum, the thickness of oil film in the journal bearing, the intensity of the ultrasound emission of the bearing etc. These parameters may in certain cases offer more reliable malfunction identification. Experimental investigations conducted in this work, on real machine equipment and in real exploitation conditions, have shown this method to be reliable in the identification of malfunctions in journal bearings. As a result of implementation of $D F J B$, the time necessary to collect measuring data is significantly shortened, whereas the diagnosis procedure for journal bearings is highly simplified. This is particularly important in complex technical systems with a vast number of measuring points, which often result in the overload of the operator.
\end{abstract}

Keywords: bearing vibration; fuzzy operator; journal bearing; prediction

\section{INTRODUCTION}

Journal bearings have found a great application in heavy machines, for instance in mills, turbines, grinders, in rolling and minting machinery, presses etc. Crucial advantages of this type of bearings are their high loading capacity and long lifetime. Therefore, the study and development of prediction methods of failure in journal bearings is very important scientific and technical issue nowadays [1].

Main causes of the damage and failure of journal bearings, include construction aspects, material selection, material imperfections, as well as the production, processing, assembly, control, examination, storage, transportation and maintenance procedures, where the bearings may suffer unexpected overload, mechanical or chemical damage [1].

The failure and damage are commonly manifested as wear, fracture and material plastic deformation, and these failure types may be classified, according to the material characteristics, into two categories. One is related to and dependent upon the material strength, while the other is a function of tribological processes on coupled surfaces of a bearing housing and a sleeve. So that the fracture and plastic deformation are the failures dependent on the material strength, while the wear in its various manifestations, is related to the tribological processes [2, 3].

The two most important indicators for failure prediction in journal bearings are the analysis of the dynamic behaviour of the bearing, i.e. the vibrations analysis, and the analysis of bearing temperature, i.e. thermal analysis [4-7]. The analysis based on vibrations monitoring is the most reliable method of technical diagnostics [8-14].

On the other hand, the increased friction in a bearing is a result of inadequate lubrication or a defect, and so the bearing temperature is an indicator of the bearing lubrication, damaging, but also this parameter may tell us if the loading and the rotation rate are adequate. Furthermore, the temperature records may give useful data regarding the function of the cooling system or the presence of unpredicted external heat sources $[15,16]$.

By using fuzzy logic, it is possible to process the indications from temperature measurements in parallel with indications from vibration measurements, and integrate them into a unique, integrated indicator of journal bearing malfunctions. This can be accomplished in a way that the signals from the temperature and vibration recording will be processed with disjunctive-probabilistic fuzzy operator. The final result is a signal which contains the information on both the bearing temperature and vibrations [4].

Finally, it has been shown that fuzzy logic gives good results in the analysis of the state of mechanical elements and technical systems $[17,18]$.

Fuzzy logic is also proving itself to be a powerful tool when used for knowledge modelling [19] particularly when used in condition monitoring and diagnostics applications [20-24].

\section{THE DEVELOPMENT OF VIBRATIONS-TEMPERATURE INDICATOR OF MALFUNCTIONS IN JOURNAL BEARING}

Fuzzy sets are, briefly, sets with gradually placed limitations, which means that the variables possess the possibility to belong with a certain percentage to a certain set of data [21]. Oppositely, in classic sets, defined in 1874 by German mathematician Georg Cantor, variables may or may not totally belong to a certain set, i.e. classical sets have solid limits. The need for defining fuzzy sets appeared because in a real world, things are rarely black and white.

Additionally, for each variable in a fuzzy set, $t$, a membership function $x(t)$ is defined, where the $x(t)$ may have values in the range between 0 and 1 . The functions may be given in an analytical or tabular form, and their shapes may be different, such as triangular, trapezoidal, Gaussian or sigmoid, as presented in Fig. 1.

Fig. 2 shows the case of the membership function $x(\theta)$ for the temperature of the journal bearing, which belongs to the fuzzy set named "overheated bearing".

It is seen from the figure that the bearing temperature is satisfying if it is below $60{ }^{\circ} \mathrm{C}$, while at higher 
temperature, a fuzzy area "warning" appears between 60 and $100^{\circ} \mathrm{C}$, and finally the fuzzy area "overheated bearing" above $100^{\circ} \mathrm{C}$.
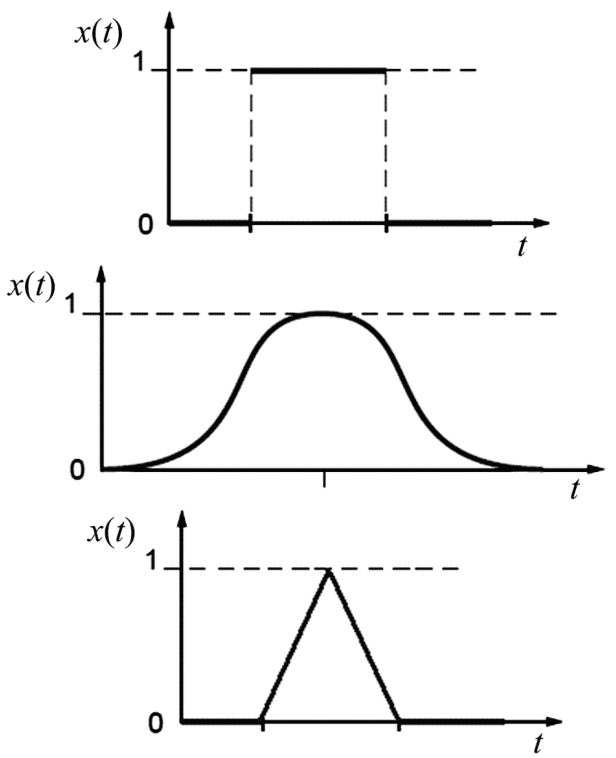

Figure 1 Membership function shape examples

It is important to bear in mind that one variable may be assigned with more than one membership function. For instance, the bearing temperature may be assigned, besides with the function "overheated bearing", also with a function named "bearing optimally heated" or with some other function.

By using membership function, we are able to perform the so-called fuzzification, where real numbers are transformed into fuzzy values. For instance, $80{ }^{\circ} \mathrm{C}$ may be converted into the value 0.5 , as Fig. 2 depicts.

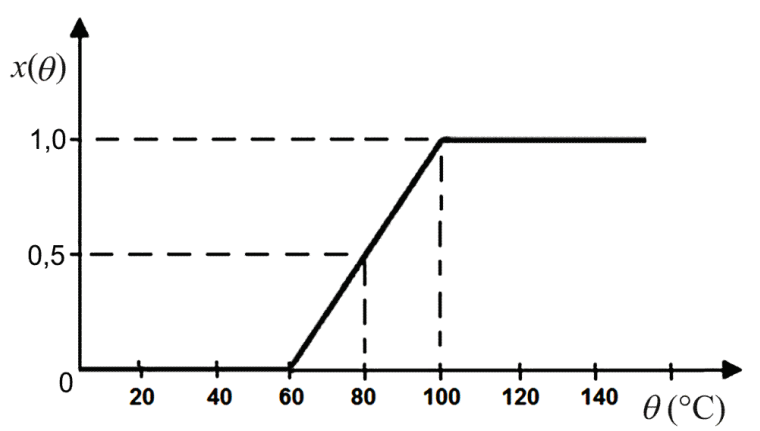

Figure 2 A membership function belonging to the fuzzy set "overheated bearing"

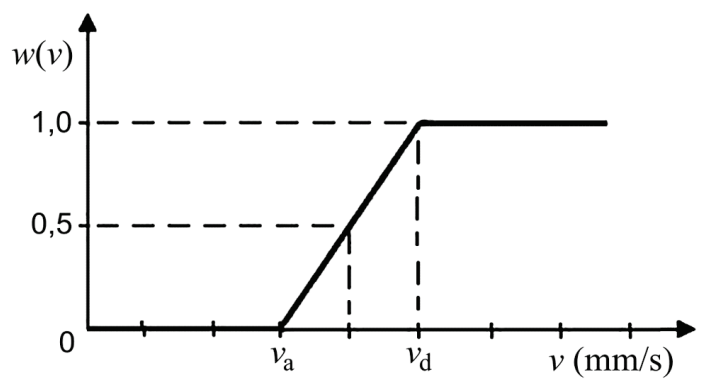

Figure $3 \mathrm{~A}$ membership function of the fuzzy set called "excessive bearing vibrations"

In the same manner, a membership function "excessive vibrations" $w(v)$ may be assigned to the fuzzy set named "bearing excessive vibrations" as illustrated in Fig. 3.
The vibrations level is satisfying in the domain up to the value $v_{\mathrm{a}}$, then the warning area is in the range $v_{\mathrm{a}}$ and $v_{\mathrm{d}}$, and excessive vibrations are marked with an area above a value $v_{\mathrm{d}}$. To conclude, the vibration limitations are $v_{\mathrm{a}}$ and $v_{\mathrm{d}}$, whereas the temperature limitations are $\theta_{\mathrm{a}}$ and $\theta_{\mathrm{d}}$.

Analytical expressions of the functions "overheated bearing" and "excessive bearing vibrations" are given by the set of Eqs. (1) and (2) respectively:

$$
\begin{aligned}
0 & \text { for } \quad v<v_{\mathrm{a}} \\
w(v)=\frac{v-v_{\mathrm{a}}}{v_{\mathrm{d}}-v_{\mathrm{a}}} & \text { for } \quad v_{\mathrm{a}} \leq v \leq v_{\mathrm{d}} \\
1 & \text { for } \quad v_{\mathrm{d}}<v \\
0 & \text { for } \theta<\theta_{\mathrm{a}} \\
x(\theta)=\frac{\theta-\theta_{\mathrm{a}}}{\theta_{\mathrm{d}}-\theta_{\mathrm{a}}} & \text { for } \quad \theta_{\mathrm{a}} \leq \theta \leq \theta_{\mathrm{d}} \\
1 & \text { for } \quad \theta_{\mathrm{d}}<\theta
\end{aligned}
$$

A disjunctive-probabilistic fuzzy operator is calculated by using Eq. (3), where $x$ and $y$ are variables having values between 0 and 1 .

$$
z=\operatorname{probor}(x, y)=(x+y)-x \cdot y
$$

With the application of the calculated fuzzy operator, one may define a defect factor of journal bearing, $D F J B$, the indicator based on vibration and temperature measured data, as:

$D F J B=(x(\theta)+w(v))-x(\theta) \cdot w(v)$

It is understandable that $D F J B$ is an integrated defect indicator, because it contains the information on both the bearing vibrations and temperature.

If the temperature and vibrations are in the permissible limits, i.e. below the "warning area", then the $D F J B=0$, while, if at least one of the variables is above the dangerous limit (excessive vibrations or overheated), then the DFJB $=1$, which is in accordance with disjunction rules.

Finally, if any of the two parameters has the value, which is in the "warning area", then the $D F J B$ is placed in the fuzzy domain.

To take a concrete example, if the value of the bearing temperature is in the permitted limitations, then the fuzzy variable has the value $x(\theta)=0$, and the fuzzy variable $w(v)$ has the value 0.3 as a consequence of a slight increase in vibrations intensity.

Then the calculation gives $D F J B=(0+0.3)-0 \cdot 0.3=$ 0.3 . In the second example, when both fuzzy variables hold value 0.5 , we get $D F J B=(0.5+0.5)-0.5 \cdot 0.5=0.75$.

In previous research [23], vibrations of a bearing body were monitored, but the procedure is the same if the rotating vibrations are taken into account, measured through the shifting of the journal or the bearing shaft.

The analysis may be expanded with the inclusion of the vibrations frequency range, but it should be born in mind that the failure of a journal bearing in the vibrations frequency range is manifested in the form of complex higher harmonics of the basic angular frequency $2 \omega, 3 \omega$, 
$4 \omega$ etc., and that the amplitudes of these harmonics are assigned with the limitations $v_{\mathrm{a}}$ and $v_{\mathrm{d}}$, in the same way as when the limits were assigned to the total vibrations (Fig. 4) [23].

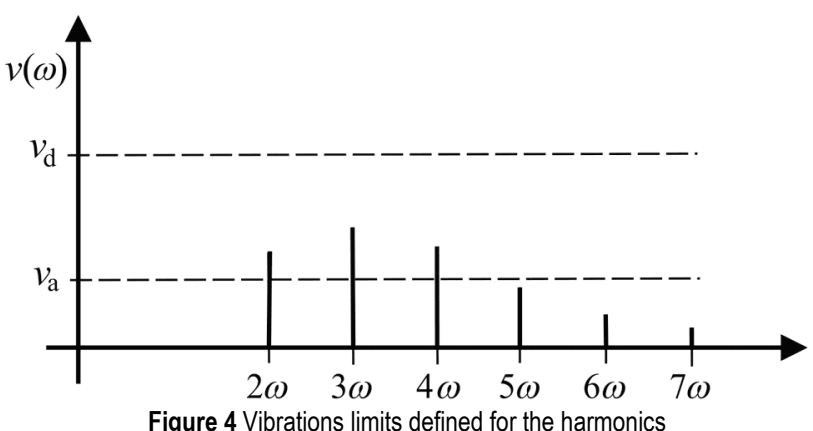

A basic harmonic component of the angular frequency $\omega$ is not taken into consideration due to the fact that the imbalance of a rotor, which is always present to a greater or lesser extent, leads to the appearance of this harmonic component in a spectrum, with significantly high amplitude.

A frequency range may be obtained by the processing of harmonics with disjunctive-probabilistic fuzzy operator, and on the basis of this range, a much more precise diagnosis may be delivered, because the interference signals are eliminated. Fig. 5 illustrates the example of the frequency range of $D F J B$.

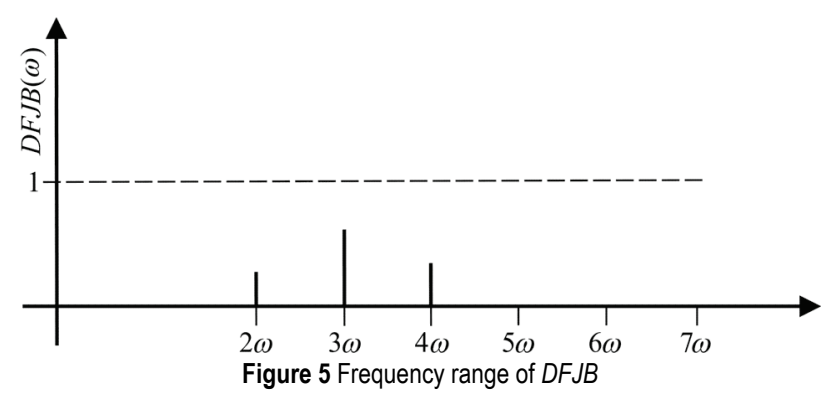

The DFJB indicator defined by Eq. (4) contains the information about a bearing temperature and vibrations, but in some applications, it may include other parameters like the lubrication oil thickness film, which will be used in the indication of the bearing state.

Of course, in these cases, the additional parameter will be incorporated into the calculation of the factor $D F J B$.

\section{EXPERIMENTAL PART}

\subsection{Apparatus for Measurement of DFJB}

An instrument for measuring the integrated indicator $D F J B$ may be operated in an analogue or digital mode. In this work (Fig. 6), a design of the instrument operated in an analogue technique is presented because it is simple to use and also the functionality of the machine element is presented in a transparent manner.

In may be noticed from the block diagram that the vibrations signal $v$ and temperature signal $\theta$ undergo the fuzzification procedure, further the signals are processed in the addition and multiplication compartments, and an output is an indicator signal $D F J B$, displayed on the instrument.

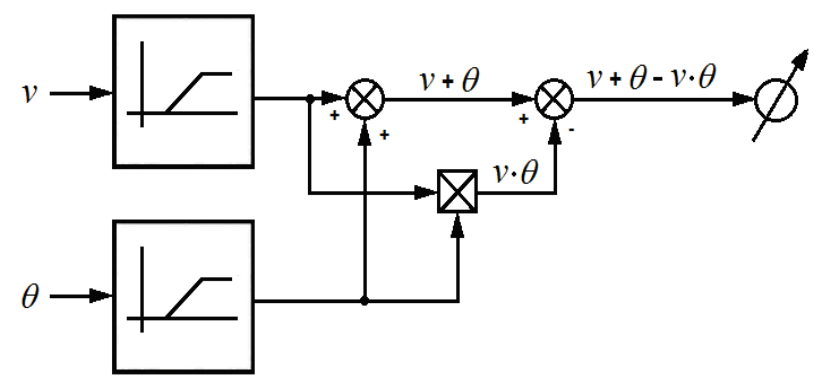

Figure 6 Block diagram of the DFJB measuring instrument

When it is necessary to analyze a frequency range, then a spectrum analyzer has to be used, and the vibrations signal processing is performed after the spectrum analysis.

The instrument scheme is given in Fig. 7. Bearing vibration measurement is carried out by a piezoelectric accelerometer with $100 \mathrm{mV} / \mathrm{g}$ sensitivity and a built-in amplifier.

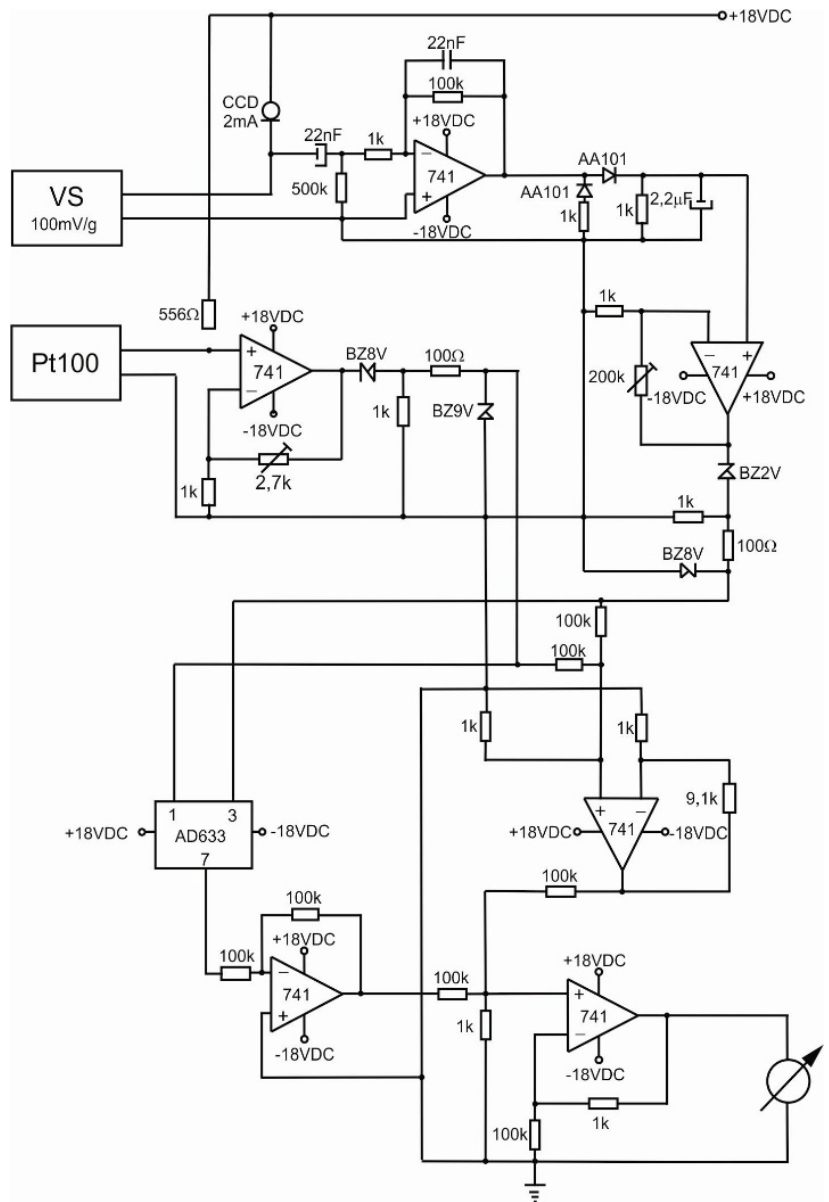

Figure 7 The scheme of the instrument for $\stackrel{\bar{D}}{D} F J B$ measurement

The IEPE - Integrated Electronic PiezoElectric accelerometer is used, powered via the CCD diode of a constant $2 \mathrm{~mA}$ current.

A vibration acceleration signal is allocated using filters and then integrated in order to be converted to the vibration velocity signal, which is further rectified and filtered.

At the same time, the bearing temperature is measured by a Pt100 sensor, powered via a resistor $560 \Omega$.

Such obtained signals are then subjected to the process of amplification and fuzzification using the limiter supplied with amplifier. 
For vibration signal, the circuit amplification is adjusted by the trimmer potentiometer $200 \mathrm{k}$, while for the temperature signal by the trimmer potentiometer $2.7 \mathrm{k}$.

The multiplication of the vibration and temperature signal is done using a set of integrated circuit AD633, and then the result is inverted.

The summation of the signals is carried out using traditional non-inverting assembly. A final signal, i.e. a defect indicator is also created in a non-inverting summation assembly.

The indication is done using galvanometer or a digital voltmeter.

\subsection{Experimental Results on Practical Equipment}

In the following section, three practical examples of the application of $D F J B$ method for the diagnostics of the state of heavy machinery equipment in cement plant in Kakanj, Bosnia and Herzegovina, will be demonstrated.

In the first case, a $1.6 \mathrm{MW}$ power electromotor operating in raw material mill, will be considered. Journal bearings are installed in the motor, with the diameter sleeve of $180 \mathrm{~mm}$, as shown in Fig. 8.

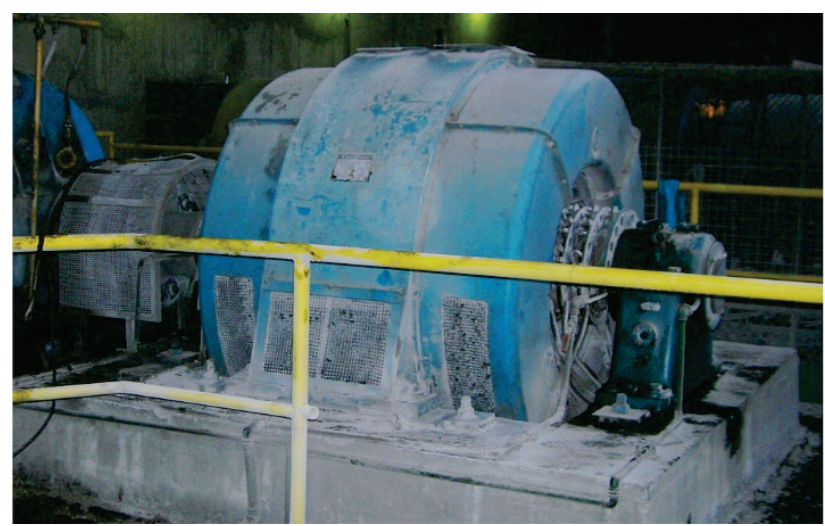

Figure 8 The 1.6 MW power electromotor in the cement plant Kakanj

The temperature and the absolute vibrations in vertical direction were measured on bearing bodies. At first bearing, the absolute vibrations were $v=9.3 \mathrm{~mm} / \mathrm{s}$ and temperature $\theta=66{ }^{\circ} \mathrm{C}$.

For this specific case, the limiting values were $v_{a}=4$ $\mathrm{mm} / \mathrm{s}$ and $v_{\mathrm{d}}=12 \mathrm{~mm} / \mathrm{s}$ for vibrations, and $\theta_{a}=60{ }^{\circ} \mathrm{C}$ and $\theta_{d}=90^{\circ} \mathrm{C}$ for temperature. The fuzzification procedure of the listed values gives the result:

$x(\theta)=(66-60) /(90-60)=0.20$ and

$w(v)=(9.3-4) /(12-4)=0.66$

$D F J B=(0.20+0.66)-0.20 \cdot 0.66=0.73$

After the bearing was dismantled, significant damages were detected on the lower hemisphere of the body, as indicated in Fig. 9.

The frequency spectrum of absolute vibrations of the bearing body is given in Fig. 10, and it may be noticed that the spectrum has the shape characteristic of worn bearing, which is in accordance with $D F J B$ calculated value and the photograph observations.

In addition, a frequency spectrum of $D F J B$ defect indicator was obtained by the analysis of vibration harmonic components, using disjunctive-probabilistic fuzzy operator, and its values are presented in Fig. 11.

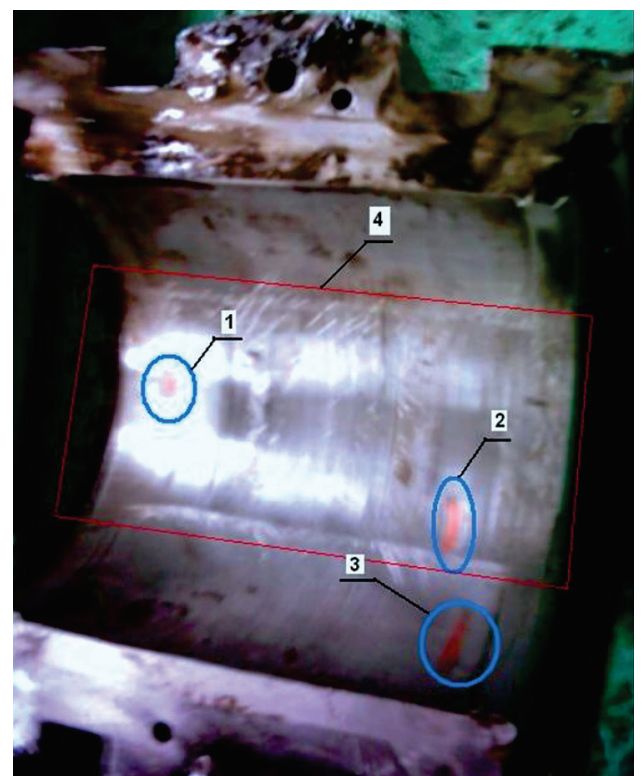

Figure 9 Photograph of the damaging of the lower hemisphere of the journal bearing body in the cement plant Kakanj

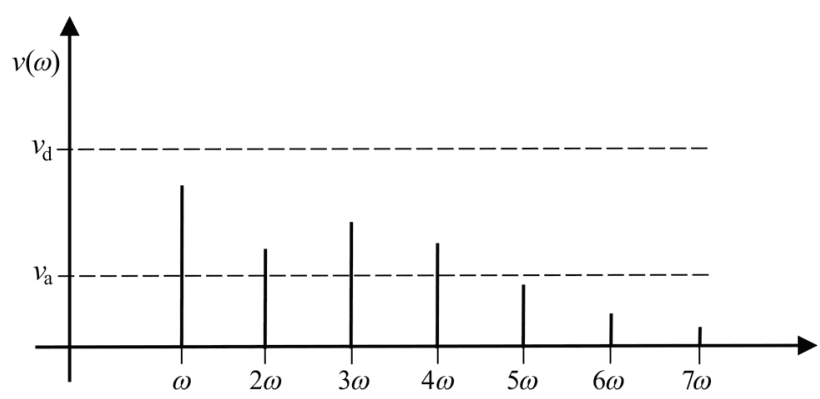

Figure 10 The frequency spectrum of absolute vibrations measured on the bearing body

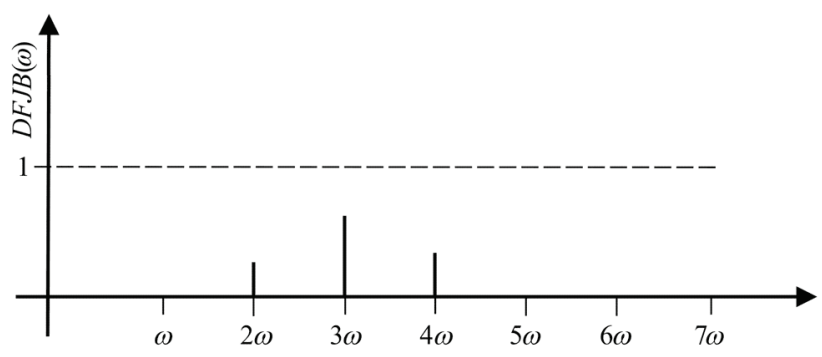

Figure 11 Frequency spectrum of $D F J B$ indicator

The spectrum shape complies to that given in Fig. 10, and this shape indicates a failure of the journal bearing.

To conclude, both the frequency spectrum of absolute vibrations and the $D F J B$ defect indicator may be successfully applied to identify the damage type on journal bearing during its exploitation.

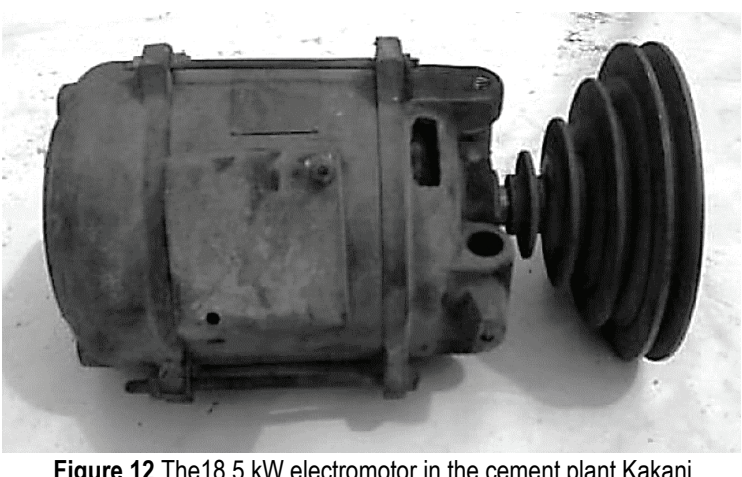

Figure 12 The18.5 kW electromotor in the cement plant Kakanj 
The second case dealt with $18.5 \mathrm{~kW}$ electromotor used to power a pollinator, with a nominal rotation rate of 1456 $\mathrm{rpm}$. The motor contained journal bearings with $50 \mathrm{~mm}$ diameter sleeve (Fig. 12).

The measured absolute vibrations of the bearing body had value $v=2.8 \mathrm{~mm} / \mathrm{s}$ and the temperature was $\theta=35^{\circ} \mathrm{C}$, while for this bearing, limiting values were $v_{\mathrm{a}}=1.5 \mathrm{~mm} / \mathrm{s}$, $v_{d}=4 \mathrm{~mm} / \mathrm{s}, \theta_{\mathrm{a}}=40{ }^{\circ} \mathrm{C}$ and $\theta_{\mathrm{d}}=60{ }^{\circ} \mathrm{C}$. The fuzzification procedure gave:

$x(\theta)=0$ and $w(v)=(2.8-1.5) /(4-1.5)=0.52$

$D F J B=(0+0.52)-0 \cdot 0.52=0.52$.

The inspection of the disassembled bearing revealed that a material of the bearing bushing was significantly frayed, proving again that an indicator based on the simultaneous vibration and temperature monitoring is a reliable tool to predict a journal bearing failure.
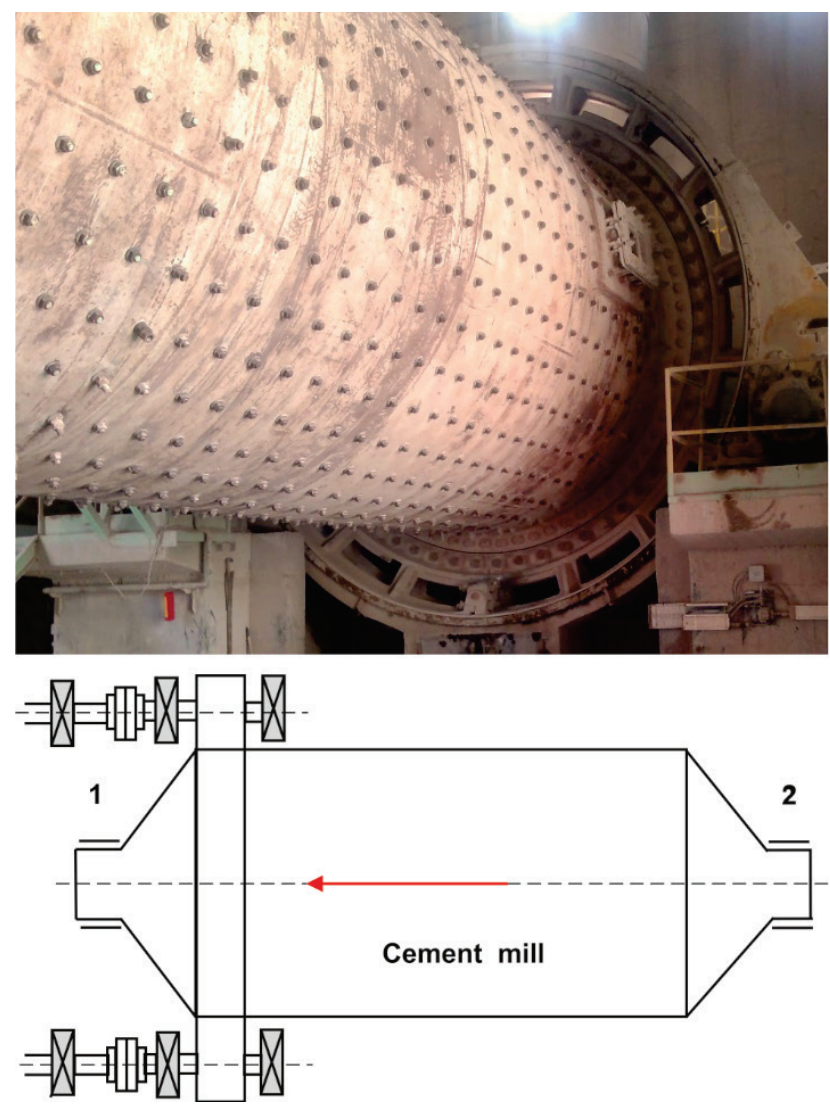

Figure 13 Cement mill in the cement plant Kakanj

The third example describes the monitoring of the journal bearings with $1554 \mathrm{~mm}$ diameter sleeve and the nominal rotation rate of $15.7 \mathrm{rpm}$, installed in the $4.1 \mathrm{~m}$ diameter cement mill, as shown in Fig. 13.

The lubrication of the bearing during the starting process was performed hydrostatically, using highpressure (200 bar) pump, while after the starting, a low pressure ( 2 bar) pump was used for hydrodynamic lubrication mode. Monitoring of the bearing under the scope gave the following raw data: the absolute vibrations in horizontal direction of the bearing body were $v=16$ $\mathrm{mm} / \mathrm{s}$ and the temperature $\theta=81^{\circ} \mathrm{C}$, while the limiting values were $v_{\mathrm{a}}=18 \mathrm{~mm} / \mathrm{s}, v_{\mathrm{d}}=30 \mathrm{~mm} / \mathrm{s}, \theta_{\mathrm{a}}=50{ }^{\circ} \mathrm{C}$ and $\theta_{\mathrm{d}}$ $=90{ }^{\circ} \mathrm{C}$.

The calculation gives: $x(\theta)=(81-50) /(90-50)=0.77$ and $w(v)=0$, $D F J B=(0.77+0)-0.77 \cdot 0=0.77$.

The analysis of the cause of the overheating revealed that the pressure of the oil pump was lower than required, due to the pump rotor deterioration. It is also evident that even in this case, the defect indicator based on vibrations and temperature measurement, pointed out to the malfunction

\section{CONCLUSION}

A diagnostics procedure for journal bearings is significantly simplified by the application of a defined indicator, which is based on the simultaneous vibrations and temperature monitoring. The reason for this is the fact that the two most important technical indicators are integrated in an intelligent way into a unique technical malfunction indicator. This is particularly important in complex systems with high number of monitoring points, which may cause the overload of the operator.

Experimental research in this work on equipment installed in a cement plant lead to the conclusion that in all investigated cases, the unique indicator based on vibrations and temperature measuring, was a reliable method for the evaluation of the journal bearing exploitation state.

Besides the processed data on the vibrations and temperature, the unique factor $D F J B$ may, in certain applications, contain and integrate data about other parameters, such as the lubricating oil film thickness or the intensity of the ultrasound emission of the bearing. So, the future studies should be directed to the optimization of the integrated parameters. In addition, future work may be expanded to the choice of different membership functions, because in this investigation, only the linear function was used.

Finally, this work proves that the fuzzy logic is very useful in the technical diagnostics, and so new results are expected to emerge in this area.

\section{REFERENCES}

[1] Rac, A. (2003). Condition monitoring and diagnosis of sliding bearing failures. Proceedings of $8^{\text {th }}$ International Tribology Conference / Belgrade, 271-275.

[2] Strecker, W. (2004). Failure analysis for plain bearings. Machinery Lubrication, July.

[3] Mobley, R. K. (2002). An introduction to predictive maintenance / Butterworth-Heinemann Publishing Company, New York.

[4] Antunovic, R. (2009). Monitoring and Diagnostics of Technical Systems / Necessarily Books, East Sarajevo.

[5] Friswell, M., Penny, J., Garvey, S., \& Lees, A. (2010). Dynamics of rotating machines. Cambridge University Press, USA. https://doi.org/10.1017/CB09780511780509

[6] Smolnicki, T., Stańco, M., \& Pietrusiak, D. (2013). Distribution of loads in the large size bearing - problems of identification. Tehnički vjesnik - Technical Gazette, 20(5), 831-836.

[7] Jovanović, V., Janošević, D., \& Petrović, N. (2014). Analysis of slewing bearing load of a rotating platform drive in hydraulic excavators. Tehnički vjesnik - Technical Gazette, 21(2), 263-270.

[8] Janjarasjitt, S., Ocak, H., \& Loparo, K. (2008).Bearing condition diagnosis and prognosis using applied nonlinear 
dynamical analysis of machine vibration signal. Journal of Sound and Vibration, 317(1-2), 112-126. https://doi.org/10.1016/j.jsv.2008.02.051

[9] Muszynska, A. (1995). Vibrational diagnostics of Rotating Machinery Malfunctions. International Journal of Rotating Machinery, 1(3-4), 237-266. https://doi.org/10.1155/S1023621X95000108

[10] San Andrés, L., Rivadeneira, L., Gjika, K., Groves, C., \& LaRue, G. (2006). A virtual tool for prediction of turbocharger nonlinear dynamic response / ASME Paper GT2006-90873.

[11] Gupta, M. \& Childs, D. (2006). Rotor dynamic stability predictions for centrifugal compressors using a bulk flow model to predict impeller shroud force and moment coefficients / ASME Paper GT2006-90374.

[12] Tam, L. T., Przekwas, A. J., Muszynska, A., Hendricks, R. C., Braun, M. J., \& Mullen, R. L. (1988). Numerical and analytical study of fluid dynamic forces in seals and bearings. Journal of Vibration, Acoustics, Stress, and Reliability in Design, 110(3), 315-325. https://doi.org/10.1115/1.3269519

[13] Antunovic, R. (2011). Development of sensor oriented dynamic rotor model as the basis of machine diagnostics. Journal of Mechanics Engineering and Automation, 1(5), 351-356.

[14] Radil, K. \& Zeszotek, M. (2004). An Experimental Investigation into the Temperature Profile of a Compliant Foil Air Bearing. Tribology Transactions, 47(4), 470-479. https://doi.org/10.1080/05698190490501995

[15] Tran, V. T. \& Yang, B. S. (2010). Machine fault diagnosis and condition prognosis using classification and regression trees and neuro-fuzzy interference systems. Control and Cybernetics, 39(1), 25-54.

[16] Zhao, F., Chen, J., Guo, L., \& Li, X. (2009). Neuro-fuzzy based condition prediction of bearing health. Journal of Vibration and Control, 15(7), 1079-1091. https://doi.org/10.1177/1077546309102665

[17] Mechefske, C. K. (1998). Objective machinery fault diagnosis using fuzzy logic. Mechanical Systems and Signal Processing, 12(6), 855-862. https://doi.org/10.1006/mssp.1998.0173

[18] Cox, E. (1994). The Fuzzy Systems Handbook-A Practitioner's Guide to Building, Using, and Maintaining Fuzzy Systems / Academic Press, New York.

[19] Zeng, L. \& Wang, Z. (1991). Machine-fault classification: a fuzzy approach. The International Journal of Advanced Manufacturing Technology, 6, 83-94. https://doi.org/10.1007/BF02601548

[20] Huang, Y. C., Yang, H. T., \& Huang, C. L. (1997). Developing a new transformer fault diagnosis system through evolutionary fuzzy logic. IEEE Transactions on Power Delivery, 12(2), 761-767. https://doi.org/10.1109/61.584363

[21] Zadeh, L. (1965). Fuzzy sets. Information and Control, 8(3), 338-353. https://doi.org/10.1016/S0019-9958(65)90241-X

[22] Rao, B. K. N. (1996). The Handbook of Condition Monitoring / Elsevier, London.

[23] Mechefske, C. K. \& Mathew, J. (1992). Fault detection and diagnosis in low speed rolling element bearings, part I: the use of parametric spectra. Mechanical Systems and Signal Processing, 6, 297-307. https://doi.org/10.1016/0888-3270(92)90032-E

[24] Mechefske, C. K. \& Mathew, J. (1992). Fault detection and diagnosis in low speed rolling element bearings, part II: the use of nearest neighbour classification. Mechanical Systems and Signal Processing, 6, 309-316. https://doi.org/10.1016/0888-3270(92)90033-F

[25] Halep, A. (2015). Vibration-temperature indicator of journal bearing defects. PhD Thesis, University of Eastern Sarajevo, Faculty of Mechanical Engineering.

\section{Contact information:}

Ranko ANTUNOVIĆ, PhD, professor

University of Eastern Sarajevo,

Faculty of Mechanical Engineering,

Vuka Karadzica Street 30,

71123 East Sarajevo, Bosnia and Herzegovina

rankoantunovicmf@gmail.com

Amir HALEP, PhD

Cement plant in Kakanj

Selima Efendije Merdanovića Street 146

72240 Kakanj, Bosnia and Herzegovina

amir.halep@gmail.com

Mihael BUČKO, PhD, Assistant professor

University of Defence in Belgrade, Military Academy, Pavla Jurišića Šturma Street 33, 11000 Belgrade, Serbia mbucko@tmf.bg.ac.rs

Sreten PERIĆ, PhD, professor

University of Defence in Belgrade, Military Academy, Pavla Jurišića Šturma Street 33, 11000 Belgrade, Serbia sretenperic@yahoo.com

\section{Nikola VUČETIĆ, MSC}

University of Eastern Sarajevo,

Faculty of Mechanical Engineering,

Vuka Karadzica Street 30,

71123 East Sarajevo, Bosnia and Herzegovina

vuceticnikola@yahoo.com 